\title{
The Habitus of Heritage: a Discussion of Bourdieu's Ideas for Visitor Studies in Heritage and Museums
}

\author{
Bella Dicks* Cardiff University
}

\begin{abstract}
This article argues that Pierre Bourdieu's conceptual framework of habitus, field and symbolic capital has much to offer museum and heritage visitor studies. However, rather than focusing on his well-known critique of high-cultural taste, the discussion here concerns displays of the 'ordinary' and social histories - of occupations, crafts, places, communities. Habitus reveals how visitors to such sites are involved in making value judgments, not solely of aesthetics but also of the social identities on display. In particular, it directs analytic attention to the active positions that visitors take up during the visit. Instead of focusing on their immediate actions and responses, however, or on exhibitions alone, I approach the visit as a moment in a person's life, where a relationship is constructed between an individual biography, a social field that assigns value to different identities, and the particular set of symbols encountered during the visit. It is suggested that these are appropriated as symbolic 'tokens' in accordance with individuals' practical relation to the world they inhabit. Past experience, memory, and class become crucial here, as these illuminate the subjective stances visitors adopt to the symbols on display, which also involve important affective and non-ideational dimensions. Data from prior visitor research conducted by the author are reanalyzed to illustrate the points made. The aim is to show how visiting is a social practice that mobilises symbolic dimensions of memory and class experience, one which cannot be understood by examining exhibit-visitor interactions in isolation.
\end{abstract}

Key words: visitor studies, heritage, museums, Bourdieu, habits, symbolic capital.

\section{Introduction: Bourdieu and museums}

Pierre Bourdieu's ideas have informed museum sociology principally in relation to art (e.g. Fyfe 2005) and markets and practices for the production and consumption of visual culture (e.g. Grenfell and Hardy 2007; Inglis 2005; Born 2010). Such work recognizes Bourdieu and his colleagues' key insight, that influencing visitors' ability to 'respond to the call' of the museum is their habitus, that is the accumulated effect of exposures and experiences in upbringing and schooling that generates adult cultural dispositions. Rather than originating in 'virtues inherent to the person', these form within the fields of 'unequal education' and socialization though which individual trajectories pass (Bourdieu and Darbel 1991: 111-12). Museums may put off visitors whose life-experiences have denied them access to the cultural ciphers that unlock the meaning of artefacts. This relational focus on symbolic environments ('fields') together with people's dispositions towards them, shaped by their conditions of existence ('habitus'), and the symbolic and economic goods this enables them to accrue (types of 'capital'), offers a powerful way of theorizing the museum-visitor relationship.

Yet there are also limitations with this approach. Two are pertinent to the papers' concerns. The first concerns working-class taste, or the 'popular aesthetic', which Bourdieu seems to approach, at least in Distinction, as a negative (a lack of 'well-formed' habitus and cultural capital) and reflective of working-class concern with immediate gratification of needs. 
This position neglects the diversity of ways in which, as studies have shown, visitors of all classes use both heritage in general, and museums in particular, to create meaning (Smith 2006). Secondly, the emphasis on hierarchies of aesthetic taste has neglected other types of cultural consumption cultivated thorough the habitus. In heritage centres and social history museums dedicated to 'ordinary life', the visitor does not confront an expression of aesthetic judgements relating to taste but a set of symbols that evoke a place, an occupation, a nation, a community, a way of life, or some other collective (Dicks 2008). Fyfe and Ross (1995) explored how such a wider understanding of habitus can be applied to local history museums, illustrating how visitors' and non-visitors' lifestyles, class, and differing geographical and social mobility afford different relationships with the local area and its artefacts.

This paper's starting point is that these more 'ordinary' forms of heritage still involve judgments not of taste but of the social value of the displayed subject. They grant legitimacy to a social identity. As such, they address the dispositions generated by the habitus, and forms of capital, just as much as do art museums. By setting out the basis on which a group and its history is to be publicly recognized and respected, they have the power to classify things, to name things, to objectify things: 'the power to make things seen ... and to make things believed, to produce and impose the legitimate ... classification' (Bourdieu 1985: 735). We all engage in remembering, but ours is the world of 'particular perspectives, singular agents'; whilst the museum's is that of an 'authorized agent' which is 'valid on all markets' as opposed to only one (Bourdieu 1985: 735). Museums comprise a 'field' of institutionalized judgments of value. How people respond to and contend with these can illuminate wider concerns: how people understand public history, what value they attach to it, how they relate it to themselves, how the past is different for different social groups. Such questions underpin the sociological importance of museum and heritage studies (Fyfe 2006).

\section{Visitor studies and the habitus: framing, appropriation and position-taking}

This legitimizing function of museums means that, in visiting, the habitus is invited to recognize and endorse the authorized value they allot to historical subjects. But how far does this actually happen in practice? What kind of value is recognized and how? Visitor studies have historically been ill-equipped to answer this. They have often approached museums as agents of cognitive and emotional change in their visitors by investigating messages 'received' or 'learned'. This tends to objectify visitors' behaviour: it becomes the object of an analytic language rather than a moment in a person's life. It also locates meaning-making as outcome of individual-exhibit relations, as in studies of exhibitions as series of stimuli or triggers. This ignores the fields of value established by institutions, suggesting that exhibitions merely transmit messages 'received' by visitors, as though these two were equivalent. The alternative, critical, (post) structuralist tradition counters such behaviourist mechanics with analyses of the exhibition-astext that recognizes its discursive power. Yet these rarely investigate actual, empirical visitors but concentrate instead on discourses inscribed within texts, objects and buildings (e.g. Karp and Levine 1991).

Both types of overemphasis on the exhibition have since led to later revisions by studies taking up an 'active audiences' perspective (as Hooper-Greenhill 2006, and Macdonald 2007, describe). Such contributions have redirected analysis towards the empirics of how visitors create meaning from within their own social contexts. This reverses linear 'transmission' models in which exhibits transmit to visitors, by seeing visitors as active decoders (see Falk's 2009 'contextual model of learning'). It involves understanding them as social actors with preformed social identities (Falk and Dierking 2000; Allen 2002; Falk and Storksdieck 2005). Socio-cultural approaches to learning emphasize its situated and context-dependent nature (Rennie and Johnstone 2006; Rennie and Williams 2002). More ethnographically-informed visitor research has investigated how meaning emerges within visitors' social interactions with each other both inside and outside the museum (Leinhardt et al. 2002; Ellenbogen 2002). Situating visitors within their contingent social interactions, as opposed to measuring their responses, has produced valuable insights into what visitors actually do in museums. Ethnomethodological research, for example, uncovers the social derivation of nuances in how they act towards both each other and exhibits (e.g. Heath and Vom Lehn 2004). 
However, the ethnomethodological approach, whilst a valuable corrective to exhibitionfocused studies, forecloses the rich analytic potential afforded by habitus. Firstly, it conceives visitors' social space as separate from the environments they encounter. Exhibits become merely neutral resources to which visitors orient their actions, gaining meaning only within this interaction. Secondly, exclusive focus on the unfolding situation occludes visitors' prior experiences and memories. Finally, its limited conception of identity sees actions as having an immediate intelligibility. This excludes how prior 'schemes of perception' and embodied residues of practical experience impinge on the situation (Bourdieu 1977). Falk and colleagues' contextual model, in a different tradition, recovers this prior formation of identity by enumerating visitors' diverse 'personal' needs and desires 'long before [s/he] ever sets foot inside an actual museum' (Falk 2009: 89). This brings a fruitful recognition of the visitor's lifeworld beyond the visit, but is problematic in seeing identity as 'inner needs' contained within the individual 'person', which can be 'satisfied' (or not) by the exhibition (Falk, 2009: 65). This depicts the self as a coherent, bounded, ready-formed identity which filters the exhibition by meeting personal needs. The 'social' is reduced to the plane of individuals interacting inside the museum (Falk and Dierking 2000). This forecloses the question of how 'selves' and 'needs' are themselves constituted through wider social practices and institutions in which cultural values circulate.

Bourdieu argues instead that we act towards things in ways adjusted to the social fields in which we find ourselves. Depicting this as merely contingent 'context', 'interaction' or 'situation' occludes the relationship between habitus (as the product of 'conditionings') and the particular 'conditions of existence' that produce and reproduce it. As Bourdieu (1977: 81-82) explains, individuals act within a 'common-sense world', where they make sense of new experiences in a manner that 'harmonizes with' all the other experiences they have had. This launches a challenge for visitor studies to find methods of accessing this common-sense practical relation (more on methodology below). Therefore, how we interact with a symbolic environment cannot be explained by focusing on the immediate situation alone (what Bourdieu calls the 'occasionalist' fallacy', 1977: 81). Neither can it be explained by analyzing behaviour as the product of social identities treated as static individual variables, whether for example social class, gender, age, etc., or as essentialized 'personal needs'. Instead, it focuses attention on the dynamics of the relationship between exhibitions and visitors, produced by 'conditions of possibility' (Bourdieu, 1977: 26), embedded in wider material and symbolic structures.

Some additional points need briefly addressing before we proceed to illustrations. The first offers a caveat to the interview data below. Recognizing the pre-reflective, non-conscious nature of habitus requires types of data that can fully reveal this. Habitus is not something that an individual can bring to the forefront of the mind and verbalize. Further, practical sensemaking is 'a state of the body', not only of the mind (1990: 68). How we use our bodies is just as expressive of habitus as what we say. Methodologically this raises challenges for researchers. Bourdieu used various survey techniques combined with in-depth interviews to try and access the habitus. However, important elements emerge in bodily responses ('heixis') such as gestures, facial expressions, silences, pauses, movements, etc. that are deeply revealing, but difficult to reach in interview (see Bourdieu et al. 1999). The data below do reveal affective dimensions, but do not give a sufficient window onto sensory and embodied modes. They are intended rather to suggest preliminary insights into the operation of habitus in visiting practice.

Secondly, these pre-reflective, embodied dimensions of habitus can be seen as challenging media studies models of decoding and encoding (e.g. Hall, 1980), which guided the research below (Dicks 2008; see also Silverstone 1988). It could be said, with some justification, that these privilege explicit 'readings' of texts, ${ }^{1}$ neglecting more affective, embodied, felt orientations. Yet there is debate on this issue. Morley's (1992) development of Hall's work proposes that audiences take up positions to cultural texts: this is suggestive of Bourdieu's own framework. It recognizes that audiences relate to texts through discursive frames originating not with the individual but within wider cultural formations, something that is occluded by disaggregating their readings into 'responses'. Further, in seeing textual elements as embedded in prior, wider cultural discourses that organize meaning, exhibitions can be seen - in Bakhtin's sense - as intertextual (Bakhtin and Volosinov, 1986). Support for this can be found in Sharon Macdonald's research in the Science Museum, which demonstrates how visitors not only decoded but 'recoded' the exhibition through prior 'cultural framings', creating 
global meanings not reducible to individual responses to individual exhibits - or indeed to this particular museum (2004).

Yet it has to be said that the notion of encoding-decoding does not fully probe how individuals' acts of decoding are unconscious improvisations, adjusted to the conditions of possibility that shape the symbolic environments encountered, and which trail the effects of prior adjustments in their wake. This brings us to the third point. The effects of habitus mean that our pasts become concretely stacked up in our ongoing schemes of action. As John Urry (1996) observes, heritage centres and museums are sites of public or collective memory; they do not store the past but rather recreate it in the present. Resonating with Maurice Halbwach's (1950) distinction between personal autobiographical memory and group-derived collective memory, both of which are socially produced, the habitus combines uniquely individual trajectories and collective classifications. The latter include 'authorised heritage discourses' (Smith, 2006) circulating in every society, and, more generally, public narratives of the past that provide 'cultural tools' that in turn inform people's consciousness of the past, which is therefore never purely individually or internally determined (Wertsch 2002). This suggests the need to investigate how memory is mobilized in visitor-exhibit relationships, both in terms of individual autobiographies and wider collective narratives.

The fourth point concerns the necessarily symbolic dimensions of both of these. Bourdieu proposes that cultural values and differences do not simply exist as intrinsic differences in societies but are grasped, as artificial differences, by individuals and groups as part of their position-taking activity (Robbins 2000: 31). Societies are full of symbols because people cannot express their actual situations and positions directly. Instead, they are offset into the cultural realm. People can obtain social advantages through unconsciously making the 'right' kind of symbolic expression. For example, by using symbols that are valued by some and not others, one establishes friendships and allegiances that match one's own habitus. Symbolic capital exchanged can therefore reinforce hierarchical class differences, not because of any greater or lesser inherent value in the symbols themselves, but because they become tokens that groups can use to express their practical relation to the world. The following analysis suggests how narratives of working-class identity offer symbolic tokens that visitors actively appropriate in quite different ways, enabling some to hold them at a greater distance from the self than others.

The final point concerns the psychological dimensions of visitor 'position-taking'. As Bourdieu affirms (Bourdieu et al.1999: 512) 'it goes without saying that mental structures do not simply reflect social structures', meaning we must understand the relationship between 'inner', psychological processes (produced by the habitus generating predispositions) and the outer universe of symbolic objects and social positions offered to the individual for investment. There may, or may not, be reinforcement between these two systems. Adapting Bourdieu's formulation to the museum context, this suggests that the symbolic world presented to visitors at a museum, like other social fields, offers a 'space of possibilities' for personal investment, a 'structured ensemble of offers and appeals, bids and solicitations, and prohibitions as well' (Bourdieu et al. 1999: 512). A museum exhibition may 'act like a language' that 'prohibits or encourages different psychological processes' generated in accordance with the predispositions of visitors' habitus. This perspective emphasizes both the symbolic power of the exhibited 'world' as well as visitors' active self-investments in it. The following discussion indicates how this active position-taking of the self, in relation to symbolic tokens gleaned from the exhibition, can become visible in visitor interviews. Ultimately I suggest ways in which such psychological processes might invite further reflection.

\section{Illustrations from research conducted}

The research, carried out nearly two decades ago, consists of interviews with visitors to an industrial heritage museum in Wales. ${ }^{2}$ I have found it useful to return to these interviews, thinking anew about how visitors describe the world they are exhibited, what it symbolizes, and how this relates to the social positions they take up in their accounts. This approach has come to modify my previous reading of 'decodings'. The study site is an ex-colliery where exminer guides, together with audio-visual shows and other exhibits, tell the story of Rhondda Valley miners across a boom-and-bust century stretching from the discovery of coal, through 
the 1920s strikes and the Great Depression, until the 1950s and industry nationalization. As mentioned above, the original research examined the relationship of encoding (how exhibitions were conceived, designed and produced), with 'text' (the exhibition narratives and images) and with decoding (how visitors make sense of them). After conducting 26 visitor interviews prior to and after the visit, I found a notable homogeneity in visitors' decodings. They all recounted the miners' story as one of hardship and struggle, offset by the closeness of their community, and they all felt this struggle was justified. Indeed, visitors all 'related to' the exhibition as a whole through a cultural framing (Macdonald, 2006) that resonated beyond the museum's walls. Such a position references a meta-narrative inscribed within popular consciousness by many UK cultural texts (film, tv, songs, novels, plays, etc.) that celebrates the figure of the working-class 'hero' who overcomes adversity in the face of circumstances keeping him - or, sometimes, her - down. It is a 'cultural tool' (Wertsch, 2002) that attaches popular-cultural value to the struggles of the industrial working-class (see Munt, 2006; Beynon, 2001). The museum's encoders were capitalizing on the pre-existing symbolic potency of this intertextual meta-narrative: it was one to which visitors could 'relate'.

What was remarkable about this 'fit' between encoding and decoding was that visitors reproduced the same meta-narrative regardless of their social class position, gender, age, locality, ethnicity. Nevertheless, underneath this, there were many lower-level differences in the detail of the story as visitors recounted it. Whilst some perceived a story that was 'finished and done with', belonging to the past and not the present, others related it to the contemporaneous context. Further, some visitors expressed a more intense and emotional connection to it than others. At the time, I did not disentangle these differences in any great depth, identifying them as differing 'orientations' to the past, but not relating them closely to interview material that touched upon visitors' own life-experiences. Returning to this in the light of Bourdieu's framework, I found that the notions of 'habitus' and 'position-taking' towards symbols offered new ways of making sense of what was going on in this piece of visitor research.

Three contrasting interview accounts illustrate one dimension of the operation of habitus. The Rogers family, the Whites and the Andersons, like other interviewees, comprised separate visitor parties who did not know or encounter each other. Of working-class origin and in late middle-age, they all lacked educational qualifications and held manual, working-class occupations. I will focus first on two of the women, Mrs. Rogers and Mrs. White. Mrs. Roger's father had been a miner in Merthyr (a nearby valley), together with her uncles, and her mother was from the Rhondda, another area of Wales. Her parents had moved away from the Valleys before she was born, and had brought her and her siblings up in Newport, a run-down, exindustrial coastal town about 30 miles away, where her father had first worked in the steelworks and later in the chemical factory. Before their visit, they said they were hoping to see 'the old way of living in Wales'. Afterwards, they both expressed, as others did, a clear framing of the story as the miners' 'just struggle', in which the picture was one of 'hardship and poverty' and yet 'closeness of the families'. However, for them, this story of 'pretty horrendous' conditions, in which men 'worked hard and lived hard' and where 'women were second-class citizens', referred only to a time of 'early struggles', of the 1920s and 30s, which Mrs. Rogers declared 'more legitimate' than later ones'. ${ }^{3}$ She then stated that the industry's more modern aspects would not interest her. This clear-cut demarcation between past and present is a recurring theme in Mrs. Rogers' remarks throughout the interview, unlike another visitor with similar mining connections, Mrs. White.

The Whites were a London couple in their 60 s visiting the museum whilst staying with their older cousin, resident in the Rhondda. Mr. White had pursued a manual trade, first in sheet metal working and then aircraft engineering. Mrs White was a retired music teacher. Her grandfather and father had both been miners in the same colliery that had since been converted into the museum. Her family had left the Rhondda when she was aged three to find work in London. She, too, described the miners' story as a 'just struggle', one where 'life was hard' but 'there was tremendous neighbourliness and closeness in the community'. In this respect, both sets of visitors framed the story in similar terms. However, Mrs. White used the miners' story to ask questions of the present: she remarked 'it's the despair of it [today]. What are they all doing now [that the mines have closed]?' Further, the two interviews exhibit different affective orientations to the story. Mrs. White said, 'You know, it's when you're Welsh, you have [long 
pause] I think there are peculiar traits of the Welsh people, and I could've very easily sat and wept when we were going round because I found it very, very emotional. It's brilliant, it's the best place l've been to'. Her voice was animated as she declared: 'It was as though you were there with them, the miners'. Mrs. Rogers also reacted emotionally to the story. In her case, though, this was not the feeling of being personally connected to it, but rather the opposite. What her account expresses above all is a sense of shock at the hardship and privations that miners had to endure. She said, 'the stark reality of the poverty really got me'.

Mrs. Roger's account suggests she positioned herself as distant from the symbolic world on display at the museum. Not only did she locate its relevance firmly in the past, not the present, it was also a story of 'others': people who lived in shocking hardship, seemingly unrelated to her - even though they were her own ancestors as much as Mrs. White's, who positioned herself as very close to it. How to interpret these differences? Without wanting to read too much into the data, there are clues. In particular, Mrs. White mentioned that she'd 'heard so much from my parents about the same things that were in the film' such as her father 'talking about the pick and shovel and sometimes just being on their stomachs cutting the coal, up to several feet in water'. She affirmed: 'I can remember as a child the men coming home all blackened' as well as their 'singing'. Since she had left the Rhondda at age three, most of her memories must actually be of her father's stories, and yet she had almost projected herself as a child into the heritage images (which include many photographs of miners' blackened faces, and plenty of singing). By contrast, Mrs Rogers said, 'I don't think my mother and father ever sat down and talked about the past'. She described as a girl going to visit her grandparents near Merthyr, where they 'lived on the side of a mountain', 'both spoke Welsh' and 'always dressed in black'. Her tone of voice here expressed a sense of their 'otherness'. Her habitus has seemingly disconnected her from these early links to the Valleys. The elderly, Welshspeaking grandparents with their old-fashioned clothes were possibly quite 'other' to the young family who had moved south to escape the poverty of the 1930s and preferred not to speak of the past. Mrs White's account, by contrast, conveys a stronger sense of personal connection to the miners' story. Although she'd lived all her life in London, her family milieu was full of stories about it, especially from her father. The visit brought these memories to the surface, the interview suggests - framed through a narrative of her own Welsh identity and belonging.

Thus, although these two women reacted to the exhibition in similar ways, 'decoding' a similar story, and shared similar close personal connections to Rhondda mining history, striking differences emerged in the positions they took up in relation to it. These suggest a contrast between more distal versus more proximate affective relations to their families' historical class experience. Their fathers' common need to escape unemployment in the inter-war years relocated both women away from the Welsh coalfields, yet this has resulted in a process of forgetting in one case and remembering in the other. Working-class generational experiences of moving for work can be said to invite different, possibly contradictory, senses of where the self then belongs: in some cases, a clear line might be drawn in a family between now and the past; for others, there may be a desire to recall and even dwell on it (differently from more careeroriented, middle-class trajectories - as Fyfe and Ross' 1996 work suggests). What seems to be salient here is the nature of the symbols that the 'story' is grasped as communicating. How does it speak to the visitor? What kind of symbolic speech-act does it perform?

The answer seems to be as much about the present as the past. In Mrs. White's account, the story seemed to act as a symbol of 'roots' - affirming her Welsh identity and identification with her late father. Mrs. Rogers, meanwhile, appeared to grasp it as the symbol of an alien world of hardship and suffering, which she located in the distant past, as 'finished'. Yet she could imagine herself in it: 'Oh My God, fancy living in those days!', she exclaimed at one point. It is notable that the Rogers family were not very far removed from hardship themselves. As a chimney sweep, her husband said he struggled to make a living now that people only use coal fires on special occasions; she described herself as a market researcher, which may or may not have provided secure employment. Nevertheless, whatever the family's actual situation, it seems clear that what the story symbolized was a material ancestry - her own - that was considerably worse than how she had imagined it: it came as a 'shock'. It does not seem too far-fetched to interpret her response of 'not being interested in the modern' as an affirmation of symbolic distance between this past and her own self, an act of assigning them to two different 
symbolic worlds, a strategy similar to what Bourdieu described as 'avoidance strategies' (1990: 61). In spite of her husband's current occupational concern with coal, her habitus had led her away from the world within which it was historically produced, and symbolically valued. Mrs. White's had rather led her to affirm this identity as her own, despite (or because of?) the complete severing of material connection to it in her adult London life.

Again, it should be emphasized that these interpretations are offered tentatively, with the aim of illustrating the value of habitus as heuristic concept, rather than as strong claims derived from thick description of the women's habitus (that life-history interviews, for example, could provide). Nevertheless, it is plausible to suggest, using Bourdieu's terms, that embracing the miners' history as 'self' afforded Mrs. White some symbolic capital, at least in the 'field' of identity-claims valued by her family. It seemed to confer a sense of working-class belonging, Welshness and 'authenticity', in a habitus formed within a milieu of stories and relationships that resonated with it. Mrs. Rogers did not apparently derive capital from this particular set of symbols, asserting distance from such, perhaps because the practical consciousness generated within her childhood experiences involved a silencing of the past and less of a 'holding onto' Welsh identity. Symbolic distance can serve to deny objective links. This 'offsetting' of objective class-position into the cultural and symbolic realm is precisely what Bourdieu's work illuminates. It is particularly visible in the case of visitor 'returnees' like these: people from the Welsh diaspora whose families once lived in the Valleys but have long since moved away, a common visitor category in the sample. Such visitors are confronted with a symbolic world that depicts the historical situation of their own families, and they are invited to relate it - or not - to their own personal heritage, to take up a position inside the story. Yet the very pastness of this 'returnee' positioning also frames the story as a symbolic object that is separate from the self (held close, in Mrs. White's case, but not the same). The Anderson family, by contrast, absorb it into their very habitus, so it ceases to be an object at all. Although they have no connections to Wales, it is they who take up the position of greatest self-equivalence with the story.

Mr. Anderson was an ex-miner, an electrician, from the Lancashire coalfield, who had lost his job 5 years previously when his colliery closed. Mrs. Anderson was a housewife. Both left school at age 15 with no educational qualifications. Both of their fathers were miners, along with many other close relatives, and, unusually, their son was a miner, too. On holiday in Wales with their grandchildren, their habitus was still immersed in the ongoing realities of mining areas. They appropriated the content not as a story as such, but through a practical consciousness that fully knew 'what's gone on here', as Mr. Anderson put it, so that none of it 'comes as any great surprise'. The story assumed a common sense rather than a mythic quality. Like others, they described the miners' 'just struggle', but framed it using a 'we' position: 'We're in a different part of the country but it's all more or less the same', said Mrs. Anderson, 'it's just in the family, in the blood.... it's just the same as us, it's just families and working, and when you've been brought up with it, you don't think of anybody, anything else'. The repeated word 'just' conveys this practical sense of a given world that they share. This couple never used words such as 'hardship' or spoke of being 'amazed' or 'emotional'. Later, Mrs. Anderson observed, 'everything's changed; as time goes on, this will just be nothing'. She added, 'once that's gone, you have to start again with something else. You can't know whether the families will break up or separate. We don't know. We may as well wait and see what happens.' Here, this 'nothing', this image of an inevitable vanishing, seemed to act as symbol of her own uncertainty about their future in Lancashire. It was as though they too felt they would soon be 'gone'. In sum, their account contains very little in the way of objectification: the frequent slippages between third and first person underline the common-sense feeling that 'it's just the same as it is round our way', a symbol of their own habitus.

Two final visitor interviews, selected from the more middle-class half of the sample, reveal a different contrast. Both Mr. Alan (visiting from Canada with an extended family party) and the Easton family (visiting from Southampton on a camping holiday with their children) held professional posts. Mr. Easton had a Geography BAand a diploma in Town Planning. Mrs. Easton had 'A' Levels and an Accountancy diploma. They both worked for local government, she as a part-time auditor and he as a planning officer. Mr. Alan (the only one of his party interviewed) was a university professor of international politics. 'It's my mother's tour', he explained, adding 
that her grandfather had been a Rhondda miner whose family had emigrated to Canada in the nineteenth century, long before she was born. His habitus had evidently granted him no practical consciousness of mining as a way of life: he offered no handed-down stories, inside knowledge or memories in interview. What he did know was a good deal about UK politics, and it was through this frame that he presented the story as a symbol of 'solidarity', a political 'force' and the miners' story as a 'culture rather than an occupation'. When I asked his view on this culture he said it 'resonates' with him 'because I teach politics'. He added, eloquently, I'm just sorry that the miners have been so defeated... from being a powerhouse, it's now a culture which has basically lost in terms of political power in Great Britain... and a certain force is flickering, if not dead, in Britain, because of it.' This positions the Rhondda as wider symbol of political struggle in the UK, which neutralizes any idea that it is a unique place. Instead it accrues symbolic capital in the field of left-leaning political history. This symbol seems distanced from Mr. Alan's own habitus, and indeed he framed it as an object of political scientific knowledge. Nevertheless, by saying he was 'sorry' about the defeat of a 'culture', he displayed an emotional investment in it. Thus his account inserts the miners into both an intellectual and an affective frame where they symbolize the loss of a way of life.

For the Eastons, too, the story was an intellectual symbol. However, they positioned the miners' way of life as outmoded (rather than defeated). Far from emblematic of a wider political story, the Rhondda was 'a very unique place', where 'they seemed to set their own standards and rules' and where the 'very difficult working conditions' meant there was 'a tight knit community' so 'if there was a crisis they all stuck together'. They explained that due to Mr. Easton's studies in industrial economics, the couple used to visit the Welsh coalfields in the 1970s, where they found the Valleys to be 'really grey, depressing places'. 'It was just horrendous,' said Mrs. Easton; 'grim'. But 'it doesn't look too bad nowadays', she added, since 'so much has grown over now'. Mrs. Easton wanted to know what 'measures they've taken now to improve the landscape and put things back to how they were before the mines'. They found much of the story 'amazing' (e.g. 'incredible to think of these people wandering around having left their place of work plastered in dust'), and expressed a keen appreciation of how things had changed today with 'health and safety standards controlled on a national level', so 'everyone's got a certain standard', 'conditions are very much better' and 'people are less likely to be militant'. They filtered this story through a habitus that - like Mr. Alan's - largely grasped it in abstract terms. It was an object of intellectual fascination that they held at arm's length: as Mr. Easton affirmed, 'I found it all very interesting'. However, unlike Mr. Alan's more affect-laden sense of regret, they took up an aesthetic position that constructed the Rhondda as journeying from the 'grim' greyness of the 1970s to a re-greened new era, where its mining history receded from view and new employment opportunities were arriving. The story was a symbol of an old way of life and hardships now consigned to the past, thanks to modern standards and systems. This position resonated with the couple's employment as local government officers, where bureaucratic knowledge constructs geographical areas as amenable to planning and improvements. In this field, the Rhondda story probably holds little symbolic capital, unless it can be grasped, as here, as a story of modernization and replacement.

\section{Discussion and conclusion}

In the above analysis, I have suggested how attention to 'position-taking' and habitus can reach beneath the level of superficially-similar visitor 'decodings' to illuminate the nuances of the active, symbolic relationships produced between exhibition and visitor. Whilst not exhaustive or generalizable, the examples discussed are suggestive and have implications for the methodologies used in visitor studies. Firstly, they suggest that - as Bourdieu (1984; 1990) and Morley (2007) both attest - social class is not a fixed attribute of individuals; it is neither a mere variable nor a single lens through which cultural values are filtered. It would be wrong to expect two people, such as Mrs. White and Mrs. Rogers, to have the same past experiences as each other, through which they can filter new experiences. They will never experience a museum visit, and appropriate its symbols, in the same way. There will undoubtedly be similarities in their habitus and lifestyles, such that they share key elements of social condition (such as housing type, neighbourhood, what type of schooling their children had, 
etc.). However, each social trajectory is unique; each life has its own non-repeatable, singular chronology of determining moments, memories, situations and environments (Bourdieu 1990: $60)$. So these two daughters of Welsh miners might share a class position, as they do with Mr. and Mrs. Anderson, but they do not share a habitus because they do not occupy the exact same conditions of existence. Accordingly, they take up quite different positions to the symbolic world of the heritage centre, as the analysis suggests, with Mrs. White appropriating it as close to her sense of self-identity, Mrs. Rogers distancing it from hers and Mrs. Anderson actively absorbing it into hers. Whilst class clearly structures these position-takings, their complexities question Bourdieu's tendency in Distinction (1984) to reduce working-class habitus to a stance of practical necessity, and are more in tune with the kinds of deep analysis presented in The Weight of the World (Bourdieu et al. 1999).

However, there is also a sense in which all three position-takings from the workingclass visitors stem from a similar principle. This is the fact that the symbolic world presented to them - of the 'just struggle of the miners' and their strong working-class community - is one that challenges them to relate it to the self. Their experiences and their memories mean they grasp it as having implications for who they are (and were). This is not the case for the middleclass visitors, who do not recognize their own identities and memories within the story and approach it as an object of knowledge. This means it is not grasped as having implications for the self. This is closer to the operation of the aesthetic gaze that Bourdieu traces in Distinction, which similarly depends on the activity of distanced appraisal (1984). Nevertheless, this kind of appraisal does not imply a necessarily disinterested stance towards the symbolic world on display. Mr. Alan's account suggests a clear emotional investment in it and a sense of regret for its loss. This is not the loss of the self (as in the Andersons' case) but the loss of a cultural ideal, a political vision. The analysis suggests that while habitus exerts its influence through unique, individual improvisations, there are classed commonalities, or 'relationships of homology' (Bourdieu 1990: 60) that return us to the more structural dimension of social reproduction.

How might 'ordinary' heritage of the type discussed here afford symbolic capital that plays a role in social reproduction? The relationship between dispositions (what visitors bring to the visit) and conditions (what they encounter) is one of adaptation, in which visitors unconsciously attend to (what they perceive as) as an exhibition's relevance to them. Whether an art museum or an industrial heritage museum, appropriating this as affirmation of the habitus accords the self the opportunity to be recognized within a publicly ratified space of cultural values. In an art museum, this is denied to those whose habitus is unadapted to the demands of the 'pure' aesthetic gaze. In an industrial heritage museum representing working-class history, appropriation is potentially open to all (it not being dependent on hard-to-master cultural codes), but is likely to take different forms. To perceive this history as an intellectual object, to understand it without having experiential memory of it (whether first-hand or second-hand), implies prior adjustments to a variety of fields in which knowledge gained is not dependent on the situated particularity of a lived experience. It becomes a form of durable symbolic capital that can be exchanged elsewhere; it is 'valid on all markets' (Bourdieu 1985: 735). To grasp it as backstory to the self, by contrast, with all the feelings of pride, nostalgia and/or shame this may imply, is dependent on location-specific, autobiographical memory and cannot, by itself, produce capital exchangeable on all markets. Our society is hierarchically structured in a way that reproduces class; Bourdieu argues that its cultural fields are key agents of this differentiation. In this sense, we can suggest that industrial heritage opens up a space for working-class visitors to feel a sense of self-value, but doing so does not in itself change the 'game' that is played in other fields. As Bourdieu and Darbel (1991) argue, these reproduce classificatory schemes which favour the detached and (apparently) disinterested gaze, valuing cultural assets that have been 'emancipated from local settings' (Fyfe 2004: 49).

Nevertheless, it would be significant if more cultural fields began to recognise and value working-class experiences and memories, beyond 'niches' such as industrial heritage or social-realist film. Therefore, a second conclusion is that we need to analyze the wider context of symbols mobilized by exhibition-making to see how cultural resonances may be shifting. Instead of heritage being detached from human action and somehow inert, we can see it as just one domain in a much wider social and cultural space, made up of a number of different fields. Any one particular social identity presented at a heritage museum gains symbolic 
'energy' from other sites of representational practice. What Wertsch (2002) suggests, together with Bourdieu's focus on the importance of symbols, is the need to look beyond exhibition narratives themselves, to see how they are intertextually and dialogically enmeshed with other narratives in wider society - including in popular culture. This means trying to understand how the 'framings' that Macdonald (2002) identifies and the narrative 'appropriations' that Wertsch (2002) explores are performed by visitors in relation to these wider sites of cultural production. Broadening interview topics to include discussion of symbols of collective identities and memories produced in different cultural sites might be fruitful here.

Finally, the concept of habitus suggests we explore not only visitors' conscious, rational evaluations of historical material but their unconscious dispositions to grasp it in a particular way. This takes us beyond 'decoding'. The role of visitors' past experiences is key here, and especially early ones in life, because, as Bourdieu observes, they 'form the basis of the perception and appreciation of all subsequent experiences' (Bourdieu 1990: 54). On the one hand, this suggests attending to how visitors express feelings towards symbols, as well as their understandings of them. Finding methods to probe visitors' life-experiences, trajectories and autobiographical memories could illuminate how affect plays a role in the visitor experience. More in-depth, lengthy and open narrative interviewing, paying due attention to non-verbal communication, together with micro-observations of visitors' embodied interactions could help reveal these more sensory and affective dimensions. On the other hand, remembering involves psychic processes that are often contradictory. Habitus is not just the unconscious repetition of habitual and familiar position-takings, as Bourdieu sometimes seems to suggest, but may involve the self being simultaneously positioned in conflicting ways, involving 'psychic defences' of nearness and distance to a range of legitimate/illegitimate positions (Born 2010). In The Weight of the World, Bourdieu does recognise how the habitus can be 'divided'. How far standard interview and questionnaire methods can reveal such division is questionable, since they invite individuals to account for their positions by articulating logical narratives of the self.

This challenges us to find ways to unfold the complex roles of affect, fantasy, defencemechanisms and intensities of desire/negation in understanding individuals' engagement in heritage. It would therefore be worth exploring more psychologically-informed kinds of interviewing and participation to probe these. Certainly, taking account of habitus does not mean, as some critics of Bourdieu charge, that he is suggesting we are condemned by some pre-existing essence to act out the same repetitive acts of perception in every encounter. Bourdieu insists that the habitus, as 'the art of inventing', is free to produce all manner of thoughts, perceptions and actions - but only those that are made possible by the 'conditions of its production'. Nevertheless, exploring the psychic complexity of habitus requires greater attention to individual subjectivities than he affords it. Bourdieu's work does, however, offer visitor studies an approach that combines analysis of the symbolic appeals launched by exhibition narratives together with in-depth investigation of visitors' subjective appropriations of them, as conditioned by their habitus. This brings their past experiences and memories, as well as knowledge accrued in other fields, decisively into play.

Submitted: November $11^{\text {th }} 2015$ Finally accepted: January $15^{\text {th }} 2016$

\section{Notes}

1 Nevertheless, it should be recognized that David Morley's (1989; 1992) development of Stuart Hall's original encoding-decoding model does capture audiences' subjective negotiations with texts, as opposed to simply readings of them.

2 This was a mixed visitor sample, in terms of class, age and gender. On class, the sample contained a higher proportion of working-class visitors $(60 \%)$ than has usually been noted in museum visitor research (for a fuller account of the methodology, see author ref), although it was too small to generalize from. Nevertheless, other studies have suggested that heritage attracts more working-class visitors than normally assumed (Smith, 2006). 
3 In relation to this exchange on the 'legitimacy' of miners' struggles past and present, it can be seen that the Rogers were implicitly engaging with another narrative, not presented at the museum, about the 1984-1985 Miners Strike, in which striking miners throughout the UK were vilified in mainstream media for taking unwarranted and illegitimate industrial action. The Miners' Strike, largely captured within this dominant media framing that castigated the strikers as 'the enemy within', had been an extremely prominent, long-lasting national news story about 15 years before the interviews took place. The Rogers were one of many visitors who obliquely or directly referred to this during their interviews, as a means of 'positioning themselves' in relation to the story of the miners' 'just struggle'.

\section{References}

Allen, S. (2002) 'Looking for Learning in Visitor Talk: a Methodological Exploration', in G. Leinhardt, K. Crowley and K. Kuntson (eds) Learning Conversations in Museums, 259-304, Mahwah, NJ: Erlbaum.

Bakhtin, M.M., and V.N. Volosinov (1986) Marxism and the Philosophy of Language. L. Matejka and I.R. Titunik (transI.). Cambridge: Harvard University Press.

Beynon, H. (2001) 'Images of Labour; Images of Class', in S. Rowbotham and H. Beynon (eds) Looking at Class: Film, Television and the Working Class in Britain, London: Rivers Oram Press.

Born, G. (2010) 'The Social and the Aesthetic: For a Post-Bourdieusian Theory of Cultural Production', Cultural Sociology 4 (2) 171-208.

Bourdieu, P. (1977) Outline of a Theory of Practice. Trans. R. Nice. Cambridge: Cambridge University Press.

(1984) Distinction: A Social Critique of the Judgement of Taste. London: Routledge.

(1985) 'The Social Space and the Genesis of Groups', Theory and Society, 14 (6) 723-44.

(1990) The Logic of Practice. Trans. R. Nice. Cambridge: Polity Press.

(1999) 'The Contradictions of Inheritance', in P. Bourdieu et al. Weight of the World: Social Suffering in Contemporary Society, pp. 507-13. Cambridge: Polity

Bourdieu, P. and Darbel, A. (1991) The Love of Art: European Art Museums and their Pubic, Cambridge: Polity Press.

Bourdieu, P., et. al. (1999) The Weight of the World: Social Suffering in Contemporary Society.,Cambridge: Polity Press.

Dicks, B. (2008) 'Performing the Hidden Injuries of Class in Coal-Mining Heritage', Sociology 42 (3) 436-52.

Ellenbogen, K. (2002) 'Museums in Family Life: An Ethnographic Case Study', in G. Leinhardt, K. Crowley, \& K. Knutson (eds) Learning Conversations in Museums, 81102, Mahwah, NJ: Erlbaum.

Falk, J. H. and Storksdieck, M. (2005) 'Using the Contextual Model of Learning to understand Visitor Learning from a Science Center Exhibition', Science Education 89, 744-78. 
Falk, J. H. \& Dierking, L. D. (2000) Learning from Museums. Visitor Experiences and the Making of Meaning New York: Alta Mira Press.

Falk, J. (2009) Identity and the Museum Experience, Left Coast Press.

Fyfe, G. (2004) 'Reproductions, Cultural Capital and Museums: Aspects of the Culture of Copies', Museum and Society 2 (1) 47-67.

(2006) 'Sociology and the Social Aspects of Museums', in Macdonald, S. (ed.) A Companion to Museum Studies [page numbers here] Oxford: Blackwell.

Fyfe, G., \& Ross, M. (1995) 'Decoding the Visitor’s Gaze: Rethinking Museum Visiting' in S. Macdonald and G. Fyfe (eds) Theorizing Museums, 127-50,

Oxford: Basil Blackwell.

Grenfell, M., and Hardy, C. (2007) Art Rules: Pierre Bourdieu and the Visual Arts, Oxford: Berg.

Hall, S. (1980) 'Encoding/decoding', in Hall, S; Hobson, D.; Lowe, A.; and P. Wilis (eds) Culture, Media. Language, [page numbers here], London: Routledge and Kegan Paul.

Heath, C. and vom Lehn, D. (2004) 'Configuring Reception: Dis-Regarding the "Spectator" in Museums and Galleries', Theory, Culture \& Society 21 (6) 43-65.

Hooper-Greenhill, E. (2006) 'Studying Visitors', in S. MacDonald (ed) A Companion to Museum Studies, 362-76, Oxford: Blackwell Publishing.

Inglis, D. (2005) 'The Sociology of Art: Between Cynicism and Reflexivity', in D. Inglis and J. Hughson (eds) The Sociology of Art: Ways of Seeing, 98-109, London: Palgrave Macmillan.

Karp, I., \& Levine, S. D. (1991) Exhibiting cultures: the Poetics and Politics of Museum Display, Washington, DC, Smithsonian Institution.

Leinhardt, G.; Crowley, K.; and K. Knutson (eds) (2002) Learning Conversations in Museums. Mahwah, NJ: Erlbaum.

Macdonald, S. (2002) Behind the Scenes at the Science Museum Oxford: Berg.

(2006) 'Expanding Museum Studies: An Introduction', in S. Macdonald (ed) A Companion to Museum Studies, [page numbers here], Oxford: Blackwell Publishing.

(2007) 'Interconnecting: Museum Visiting and Exhibition Design', CoDesign, 3 (1) 149-62.

Morley, D. (2007) 'Audience Research', The Museum of Broadcast Communications

http://www.museum. tv/.

Munt, S. R. (ed) (2000) Cultural Studies and the Working Class, London: Bloomsbury Publishing.

Rennie, L.J. and Johnston, D.J. (2004) 'The Nature of Learning and its Implications for Research on Learning from Museums', Science Education 88 (1) S4- S16.

Rennie, L. J. and Williams, G. F. (2002) «Science Centres and Scientific Literacy: Promoting a relationship with sciences, Science Education 86: 706-26. 
Robbins, D. (1999) Bourdieu and Culture, London: Sage.

Silverstone, R. (1988) 'Museums and the Media: A Theoretical and Methodological Exploration', Museum Management and Curatorship, 7 (3) 231-41.

Smith, L. (2006) Uses of Heritage, London: Routledge.

Urry, J. (1996) 'Theorizing museums', in Macdonald, S., and Fyfe, G. (eds) Theorizing Museums, [page numbers here], Oxford:Basil Blackwell.

Wertsch, J. V. (2002) Voices of Collective Remembering, Cambridge: Cambridge University Press.

${ }^{*}$ Bella Dicks is Professor of Sociology at the School of Social Sciences at Cardiff University. Her research is in the field of digital qualitative methods, heritage, museums, culture-led economic regeneration, social disadvantage and class. She is particularly interested in how places and people deal with the cultural and social dislocations accompanying de-industrialization and how regeneration strategies connect (or otherwise) with community members on the ground.

Her book Heritage, Place and Community (2000), traces the processes through which a south Wales coal-mine was transformed into a 'living history' museum, while her 2004 book Culture on Display critically appraises the contemporary regeneration focus on the production of place 'visitability'.

Tel: +44 2920875231

email: dicksb@cardiff.ac.uk 